\title{
CORPO E EROTISMO NA PRODUÇÃO VISUAL DE MÁRCIA X.
}

\author{
Luana Saturnino Tvardovskas - Mestranda em História \\ IFCH - UNICAMP
}

Nos últimos trinta anos o corpo, a sexualidade e a construção da subjetividade passaram a ser tematizados pelas ciências humanas num movimento de positivação do mundo sensível e de desestabilização de práticas que legitimavam opressões ao corpo, como a tradicional separação cristã entre corpo e alma. Neste processo delineava-se uma crítica radical à Modernidade, aos controles sobre os corpos e sentidos que furtavam estas esferas da observação e da crítica, apontada tanto pelos estudos pósestruturalistas onde se destacam Michel Foucault e Gilles Deleuze quanto pelas reflexões de teóricas feministas.

Mesmo quando o corpo passou a conquistar o centro das atenções através da proliferação das ginásticas, de dietas alimentares, das imposições disciplinares ou de relaxamentos hedonistas, ele não era tematizado e não havia se constituído ainda como um campo de discursividade, conforme explicita Margareth Rago ${ }^{1}$. Somente nas décadas de 60 e 70 ocorre uma liberação dos costumes onde os movimentos feministas, juntamente com as reivindicações de gays como o direito ao prazer, contribuíram para um relaxamento das normas rígidas sobre o corpo. Também surgiam os apelos de um mercado de consumo cada vez mais hábil e atraente, que incitava a libertação do corpo das sujeições às quais estava exposto.

Os tempos, hoje, realmente são outros, embora muitas coerções ao corpo ainda estejam em voga e cada vez mais sofisticadas, conforme atentou Deleuze acerca da atual sociedade de controle. Da moda às pesquisas científicas, os corpos ganharam visibilidade e atenção. A definição de homossexualidade como patologia já foi historicizada, a sexualidade deve agora ser vivida com intensidade e nossos corpos precisam ser amados e adulados. Nas pesquisas científicas, pode-se destacar os estudos que desmistificam os discursos sobre o corpo feminino criados pela Medicina moderna. Estes mitos causaram prejuízos diversos às relações de gênero, como ao associar as mulheres à figura santificada de Maria, provocando a destituição do desejo sexual feminino enquanto "comprovavam" a vocação

1 RAGO, Margareth, "O Corpo Singular", prefácio ao livro Corpos e Subjetividades em exercício interdisciplinar, Sônia Cabeda e Marlene Neves Strey, Porto Alegre, EDIPUCRS, 2004. 
destas para a maternidade. Também se debateu como, a partir das análises de inspiração lombrosiana do século XIX, a imagem da prostituta foi associada à de figuras portadoras de deficiência. Os estudos feministas denunciam, assim, como a leitura médica do corpo apoiou para o confinamento das mulheres na esfera do privado, enquanto a vida política, a cultura e os prazeres eram reservados apenas aos homens. Todos estes estudos são reações a um tipo de percepção do corpo que legitima o confinamento das identidades em retratos imóveis, através da associação dita "científica" entre biologia, opção sexual e status social.

Feministas têm ocupado espaços antes interditados às mulheres $\mathrm{e}$ reorganizado saberes até então produzidos dentro da lógica patriarcal, gerando importantes contribuições nas ciências, na medicina, na literatura, etc. Uma epistemologia feminista constituiu-se, acompanhando o movimento de feminização cultural (entendido aqui como processo cultural e histórico de reorganização dos regimes de saber e poder, mas também dos modos de constituição das subjetividades), impulsionado pela entrada das mulheres na esfera pública e em campos que eram somente masculinos. A partir do olhar feminista, cria-se também uma nova linguagem, específica por atentar para temas como o corpo, a sexualidade e as emoções, marcada pela queda de uma perspectiva universalizante e baseada agora em saberes localizados.

Nas próximas páginas pretende-se investigar como as reflexões feministas estão afetando ou incorporando-se ao terreno das artes visuais nesta virada do milênio e, mais especificamente como a artista carioca Márcia X. (RJ, 1959-2005) dialoga com as temáticas do corpo e do erotismo na contemporaneidade dentro desta perspectiva. É importante notar que neste registro corpo, sexualidade e subjetividade foram conectados também no pensamento e vêm sendo amplamente tematizados. $\mathrm{Na}$ atualidade, falar do corpo implica remeter-se a sexualidade e à própria percepção e constituição de si. Assim, esta artista elabora diversas dimensões dessas críticas: questiona as novas possibilidades de relacionarmos conosco mesmos, busca captar os poderes e pressões que incidem sobre os corpos e questiona as novas partilhas da sexualidade e da experiência corporal na sociedade de controle.

Quero chamar atenção a esta relação estabelecida entre a produção artística e as reflexões feministas por que desse encontro origina-se uma crítica da cultura arquitetada através de novos olhares, visto que os lugares de fala dos sujeitos modificam a maneira como concebem suas subjetividades e produzem ações no mundo. 
Márcia X. (Márcia Pinheiro, Rio de Janeiro, 1959-2005) desenvolveu desde a década de 80 até sua morte jovem, em 2005, performances e instalações questionando o estatuto da arte e do artista na sociedade, do corpo e da sexualidade, da perversão e da normalidade. Talvez não se tenha a dimensão do que significou investir nestas manobras experimentais em meio ao refluxo dos anos 80, período de franca implementação desse liberalismo do capital. No entanto, é importante situála em sua transgressão, divergente daqueles artistas que primaram pelo "retorno da pintura" neste momento de "abertura lenta e gradual" no país.

Márcia Pinheiro mudou seu nome para Márcia X. após uma performance na cidade do Rio de Janeiro, em 1985, e com parceria do poeta Alex Hambúrguer. Tratava-se de uma intervenção na Feira Internacional do Livro onde X. acabava numa nudez performática. Como o acontecimento foi registrado nos jornais no dia seguinte, a estilista homônima Márcia Pinheiro não gostou de ver seu nome envolvido em fato tão escandaloso e Márcia X. realizou a operação de anexar um "X" ao seu nome, para desvincular-se da imagem da famosa estilista das colunas sociais.

Associando elementos que se antagonizam no imaginário social como sexo, religião, infância, morte, masculino e feminino, X. produziu obras bastante expressivas se contrastadas com a profunda deserotização dos corpos resultante da banalização do sexo e de sua exposição excessiva na mídia na atualidade. Neste sentido, Márcia X. propõe um movimento inverso, de erotismo exacerbado, que parece romper com diversos esteriótipos impostos pela racionalização capitalista. Principalmente no que tange ao comércio sexual que deserotiza as relações e reforça o "dispositivo da sexualidade" 2 de captura das manifestações do desejo. Trata-se, deste modo, de uma produção artística que busca o deslocamento e a subversão da ordem instituída, como no devir deleuziano ${ }^{3}$ - devirmulher/devir-animal - que é sempre a produção de diferenças e não transformação identitária. ${ }^{4}$

2 Ver FOUCAULT, Michel, História da Sexualidade I, A vontade de Saber, Rio de Janeiro, Graal, 1977, p. 147.

3 Ver DELEUZE, Gilles; Crítica e Clínica. São Paulo: Ed. 34, 1997, p. 11.

${ }^{4} \mathrm{O}$ devir não pode ser masculino porque o Homem é a forma dominante que pretende se impor a todas as outras, enquanto a mulher, o animal, a molécula, possuem componentes de fuga que 
Este apelo erótico muitas vezes conecta-se ao modo dos surrealistas como Bataille e Breton, onde a expressão do sexo torna-se ato de rebeldia, ação insubordinada e lúdica. Márcia X. não se contenta com as imagens binárias de um feminino casto ou vampirizador. Em suas obras ela expõe e insinua o corpo, desfaz as fronteiras do normal e do perverso, afirma o prazer e brinca com o desejo. Neste fluxo não está sozinha, já que este movimento pode ser percebido em outras produções artísticas de mulheres na atualidade, como foi notado por Heloisa Buarque de Holanda no artigo "Novos Tempos"5, Revista Labrys. Holanda, reconhecida por trabalhos referentes à literatura e ao revolvimento social das décadas de 60 e 70, introduziu o debate sobre o tema das artistas visuais que produzem desde a década de 80 e rearticulam os temas do feminismo pós-moderno.

Nesta geração de mulheres artistas "pós-feministas", segundo Holanda, o olhar parece recair mais sobre o mundo exterior, um olhar que busca novas formas de intervenção e de crítica:

\footnotetext{
"No novo ethos pós-feminista dos anos 90, (...) o que se percebe é uma inclinação visceral em olhar não mais para dentro de si, mas para fora, para o mundo. Em situar-se, em mapear com precisão o território onde nos encontramos através de uma surpreendente, e até inesperada, perspectiva de gênero. E o que a nova artista vê é a violência e a desestabilização sócio-cultural modulada em várias claves: na clave erótica, na familiar, na amorosa, na social". ${ }^{6}$
}

A reapropriação de acervos materiais e simbólicos e a ressignificação de ícones modernos são apontados por Holanda como os procedimentos centrais desta nova estética: convite para nos refrescarmos com o humor transgressivo de Márcia X.

\section{Produção artística}

A seguir, algumas instalações e performances de Márcia X. serão apresentadas mais pontualmente, observando-se através do conjunto algumas das estratégias da artista referentes ao erotismo, aos corpos e às discussões de gênero.

escapam à formalização. A árvore-falo, em Deleuze, é esse poder ditatorial, o general, o chefe, que se sobrepõe aos rizomas em fuga. DELEUZE, Gilles, Mil Platôs I, São Paulo, Editora 34, 1995, p. 27.

5 HOLANDA, Heloisa Buarque de, "Novos Tempos", In. Revista eletrônica Labrys - Estudos Feministas, número 3, janeiro/julho, 2003.

6 HOLANDA, op. Cit.. 


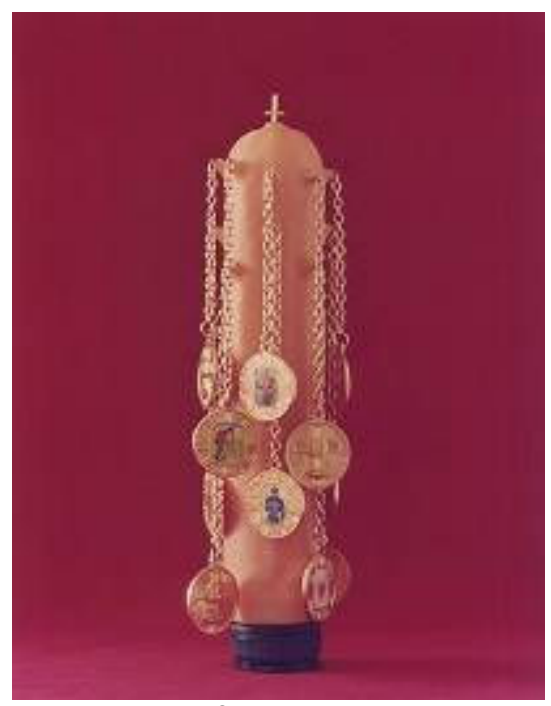

Sem título,

Série Fábrica Fallus,

1992 - 2004

“Fábrica-fallus" (1993-2005) é o título da série onde X. utiliza pênis de plástico - sempre vigorosos e eretos - comprados em sex shops e acoplados a toda sorte de enfeites femininos, apetrechos infantis e religiosos. As engenhocas sexuais são modificadas pela junção de diversos materiais: pompons, espelhos, medalhas, rendas, etc. Aí, o jogo simbólico do falo é desmontado num duplo ponto de vista: tanto pela personificação bem humorada dos pênis autômatos, que se transformam em bispos, palhaços, narcisistas, amantes latinos, etc., quanto pela expressão de um desejo feminino pós-emancipação, quiçá muito mais livre, e que se evidencia pela possibilidade de acesso a uma indústria erótica de vibradores e mil outros apetrechos criados para favorecer o prazer. Anônimos e impessoais nas prateleiras das lojas, nas obras de X., estes órgãos sexuais se transformam em objetos simultaneamente fálicos e femininos, pornográficos e infantis, sagrados e profanos. Pênis que se abraçam e enamoram, pênis coberto de imagens santificadas, pênis-candelabro, pênisnarciso que se observa num espelhinho cor de rosa, pênis-sádico, acorrentado, de todos os gostos e por todos os lados.

A fábrica Fallus é metonímia do mundo: uma maquinaria que não pára de produzir ícones do desejo, de adaptar os "produtos" a toda sorte de 
gostos, de recriar o poder do falo. Márcia X. volta seu olhar ao patriarcado ironizando nossa obsessão com a sexualidade através da fabricação em série. É uma imagem do que Foucault observou acerca da explosão discursiva sobre o sexo em nossa sociedade. Delineia-se, de modo cômico, uma crítica ao falocentrismo arquitetada através da própria prática cultural de enaltecimento do masculino. Os pênis eretos, símbolos da masculinidade e vigor são ironizados, ao mesmo tempo em que sua carga erótica é potencializada.

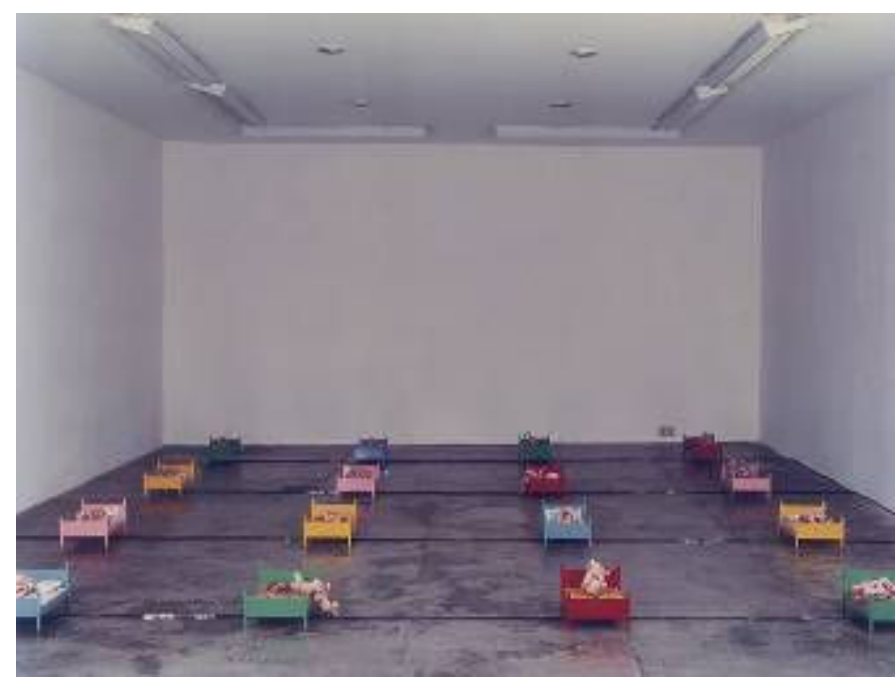

Os Kaminhas Sutrinhas, 1995

Instalação,

Coleção Gilberto Chateaubriand 


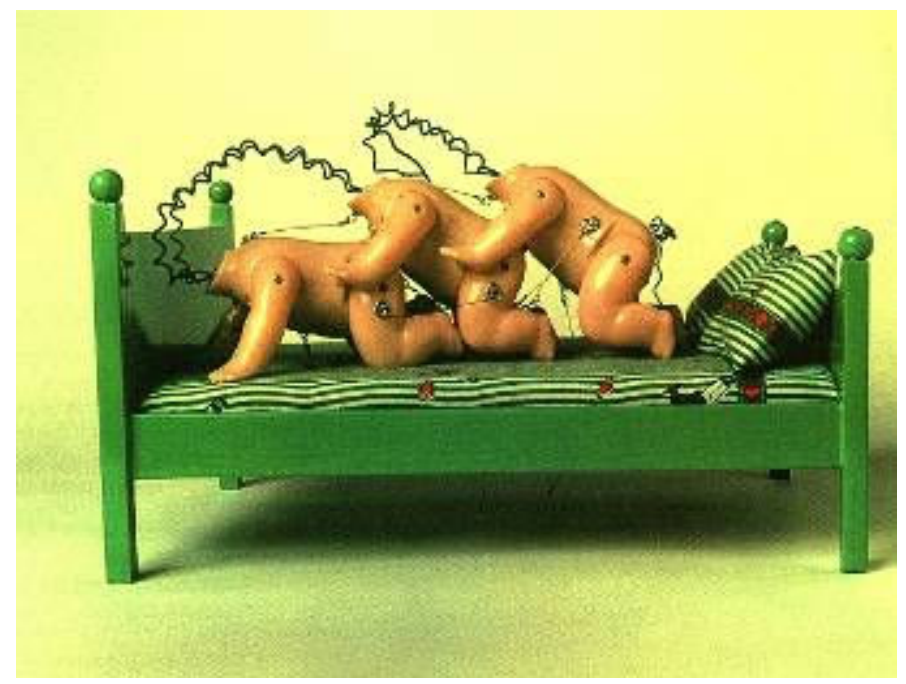

“Os Kaminhas Sutrinhas” (1995) é o título da exposição onde trinta pequenas camas coloridas ocupam o chão da galeria. Sobre elas duplas e trios de bonecos sem cabeça executam uma mímica sexual, um repertório de ações sexualizadas. Cada "kaminha" é enfeitada com bordados, possui lençol e travesseiro com motivos infantis. As roupas dos bonequinhos e suas cabeças foram tiradas restando somente corpos desprovidos de signos de identificação de gênero masculino/feminino. Os bonecos são encaixados por fios de aço e como eram projetados para engatinhar, movem-se enquanto o chip musical entoa "it's a small world", música tema da Disneylândia. Um pedal permite o acionamento de todos os bonecos ao mesmo tempo e a cacofonia de sons intensifica a violência da movimentação mecânica que contrasta com o visual suave, conforme narra a própria artista.

Contrastes fortes: o título remete ao Kama Sutra, minucioso estudo do kama (amor e prazer sexual) cujo autor Vatsayana reconhece como um dos três grandes objetivos da vida, sendo os outros o dharma (religião e moral) e o artha (riqueza e prosperidade). Para este autor, existem 64 complementos para o ato sexual, incluindo arranhões, pancadas, mordidas e outras formas de jogo amoroso, conforme investiga Eliane Robert Moraes em $O$ que é pornografia:

“Às mulheres ele brinda com ensinamentos tanto da arte de monopolizar os braços do marido, quanto a de buscar os carinhos de um amante clandestino. Aos homens ele ensina a arte da conquista e dos vários 
meios de excitar o desejo, tudo isso com uma naturalidade que revela a ausência total dos conceitos Ocidentais de pecado e vergonha" ${ }^{\text {. }}$.

É bastante interessante observar a produção de X. nestes termos onde a artista produz uma brincadeira de duplo sentido: uma crítica às padronizações da sexualidade na atualidade, vide a trilha sonora irônica do "it's a small world", plastificada e mecânica, ao mesmo tempo em que proclama novas questões acerca dos modos de lidarmos com o prazer e com o desejo.

A arte de amar - tradição perdida na atualidade - esteve presente tanto na Ars Amatoria de Ovídio na Roma do século I ou na antiga arte do Kama Sutra e tornou-se para nós livros de auto-ajuda vendidos em postos de gasolina. Tornaram-se somente poses excessivas: "kaminhas sutrinhas", associação transgressiva de X. entre as esferas antagônicas das "perversões sexuais" que são realizadas por bonequinhos infantis acéfalos. Distinção que é apontada por Foucault, quando contrasta a ars erotica oriental e a scientias sexualis moderna. A obra também é crítica de uma "sexualidade papai-mamãe", heterossexualidade monogâmica e compulsória que estimula preconceitos, poda o desejo e controla os corpos.

A erotização das crianças na atualidade também está em pauta nas obras de Márcia X. Ao defrontar sexo e infância ela sacode os tabus constituídos e cria uma zona indefinida entre a ironia e a valorização dos temas.

Infantilização do pornográfico e erotização da imagem com humor. Os espaços (subjetivos, arquitetônicos, culturais, etc.) reservados à sexualidade e ao prazer, mas também à própria infância, estão distorcidos na contemporaneidade, e X. parece ao mesmo tempo nos ridicularizar perante esta grande confusão dos sentidos e atentar para o que está sendo perdido em nossa sociabilidade. Ela associa sexo/infância comicamente, ao mesmo tempo em que ridiculariza os ícones da cultura falocêntrica, produzindo um olhar transversal. Nas palavras de Magareth Rago:

"O pornô infantilizado perde a agressividade e torna-se cômico; o infantil erotizado se torna mais interessante ao olhar adulto. Dois extremos se confundem: a perversão, o fetiche sexual, noite em lua cheia e a pureza infantil, manhã ensolarada". (Anais do Fazendo Gênero, 2006)

7 MORAES, E. R.; LAPEIZ, Sandra . O que épornografia. São Paulo: Brasiliense, 1984, p. 20. 
A erotização atravessa estas obras, traduzindo buscas por formas de expressão diferenciadas, por outras concepções de sexualidade, por novos lugares para o feminino e para o feminismo - para "além da mulher", como afirma Margareth Rago (Anais Fazendo Gênero, 2006). Até a figura da feminista "descarnada", avessa a qualquer traço de feminilidade deixou de ser o estereótipo típico neste mundo onde as mulheres não são nem mais santas ou inocentes e querem gozar sexualmente.

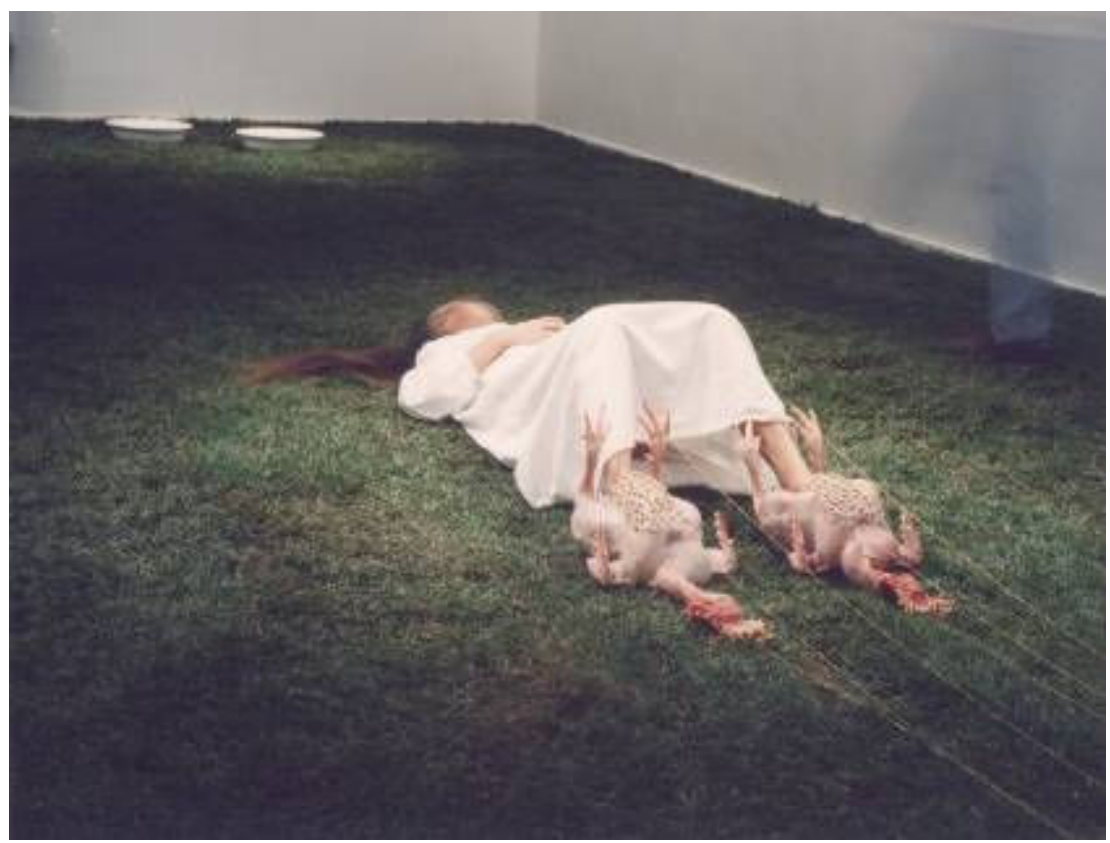

Ação de Graças, performance/instalação, 2003

“Ação de Graças” (2000 - 2002) é outra performance/instalação criada entre 2000 e 2002 que permeia obsessões culturalmente associadas às mulheres, tais como a alimentação, a rotina, a limpeza, a beleza e a religião. A pose tradicional nos consultórios ginecológicos "frango-assado", onde a mulher precisa manter as pernas abertas para ser examinada, é atordoantemente encenada por $\mathrm{X}$. que tem os pés enfiados dentro de dois galos depenados, "temperados" com pérolas. Deitada na grama, X performatiza com os elementos tipicamente femininos como os culinários. Esta imagem permanece na memória: ação de graças, thanksgiving, mais uma vez nos defrontamos com a ironia dos títulos de $\mathrm{X}$. que sugerem 
outras tantas conexões imagéticas. Qual a ação de graças ocorre nesta obra? Ou o dia é de Ação de graças e o jantar esta sendo preparado para a família? Quem é essa mulher? A virgem de branco em êxtase, a mulher no parto ou o animal/alimento que é/integra uma mulher/alimento, já que é a ave depenada aquela que recebe as pérolas, instrumento tradicional de sedução feminina.

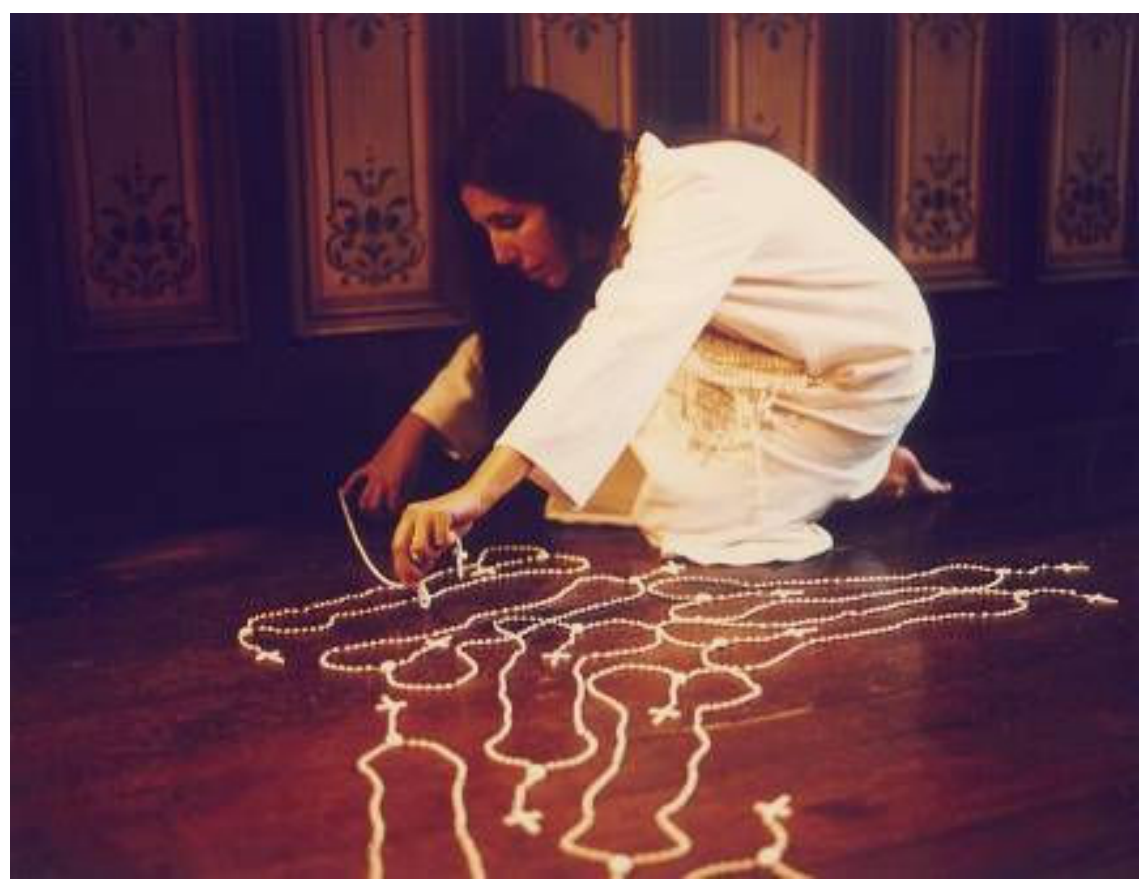

Desenhando com terços, registro de performance

Instalação realizada na Casa de Petrópolis - Instituto de Cultura (sala de jantar em processo de restauro), julho de 2000. Foram usados 500 terços (montados dois a dois). A sala mede 4 X 5m. A performance durou $6 h$.

Márcia X. também explicitou o estatuto do corpo carregado por sentidos morais e religiosos, através de performances como "Desenhando com Terços", polêmica obra que causou reações de indignação por parte da comunidade artística por ter sido censurada pelo Centro Cultural Banco do Brasil/Sp, em 2006. Nesta performance, a artista preenche uma sala de 20 metros quadrados com desenhos de pênis feitos com rosários, que posteriormente mantém-se em exposição. $\mathrm{O}$ trabalho se estende até que 
toda a superfície esteja preenchida com imagens (simplificadas, estilizadas, icônicas) do órgão sexual masculino onde a artista parece

"Arrancar de um dos símbolos religiosos algo que está ali inscrito (o perigo da carne) e que os imperativos morais da religião preferem ocultar, privilegiando o espírito desencarnado",

Márcia X., num ritual sagrado/profano, vestida de branco, com longos cabelos rebelados, evidencia que a mulher assexuada, santificada e glorificada pelo imaginário ocidental agora se radicalizou. Erotização rompante presente no gesto obsessivo e persistente de desenhar pênis com terços. Márcia X. parece reativar uma carga de potência existente na sexualidade, distinguindo-se de uma crítica rancorosa que proclama o ódio ao masculino e que acabaria também por negar os próprios corpos, o desejo, o prazer. O discurso do falo que é o discurso do poder está presente na relação obsessiva que a modernidade construiu entre sexualidade e identidade. Já na abordagem de Márcia X. existe uma imaginação sexualizada, viva e libertina, que utiliza a força do erotismo como meio de desestabilizar o próprio discurso do poder. O tema é ardiloso e por isso nos deteremos um pouco mais sobre ele.

A antropóloga e filósofa paulistana Eliane Robert Moraes trata em seus estudos acadêmicos deste universo explosivo, transgressivo e subversivo, onde a imaginação pode escapar dos limites impostos pela moralidade burguesa. Pornografia, surrealismo e as obras de Sade são temas por ela evidenciados, onde mostra que é preciso pensar filosoficamente as práticas libertinas.

O discurso libertino fala de sexo abertamente, é claro, mas também expõe, exibe, estimulando os corpos a libertarem-se da moral. Assim, ele não trata de proibir, mas de produzir a sexualidade, como bem mostrou Foucault. $\mathrm{Na}$ sociedade de consumo, muitas vezes o discurso libertino articula-se a uma organização da sexualidade que obedece aos princípios do consumo e da produção. Ordena-se o obsceno, delimitando o que é pornográfico no âmbito do que é proibido.

É como interdita que a pornografia deve ser consumida, dando vazão às fantasias reprimidas, transformando fetiches em desejos. Assim, o desejo é capturado e o que interessa é o desempenho na cama, a eficácia

8 BASBAUM, Ricardo, “'X”: Percursos de alguém além de equações”, In. Concinnitas. Revista do Instituto de Artes da UERJ. 
preconizada pela sexologia. ${ }^{9}$ Amor-livre obrigatório, afirma Moraes, "esse é o paradoxo dos nossos dias":

"Se o homem moderno liberou-se, muitas vezes essa liberdade foi realmente consumida e de forma compulsiva, como convém às sociedades de consumo. Um exemplo típico são as revistas pornográficas: cada página folheada pede outra, cada foto é uma chamada para outra, cada publicação anuncia o número seguinte". ${ }^{10}$

É o discurso libertário, na figura do pensamento feminista, que buscaria reorganizar esse território pautado pela conjunção entre moral burguesa e patriarcal, segundo Moraes. Nesse sentido, o pensamento feminista incentiva a liberação sexual, mas critica com veemência a indústria pornográfica no que ela delimita e constrange os corpos e os desejos, principalmente os femininos. Querendo produzir deslocamentos estratégicos no campo da sexualidade, as feministas buscam "reinventar o erotismo, construir novas formas de prazer, libertar o perverso, resgatar o desejo...". 11

Onde a crítica feminista incide contra a pornografia, importante notar, é neste modo atual de produção que privilegia os órgãos em detrimento dos corpos, e os corpos em detrimento dos seres. Quem sabe não possamos investir em uma pornografia que incite desejos não só masculinos, não somente fálicos ou desejos-generais? - nos questiona Moraes.

Também vale lembrar que a autora considera que a oposição dominante no senso comum entre erotismo e pornografia precisa ser repensada. O erotismo é considerado por nós como sutil e velado, enquanto associamos a pornografia ao obsceno, ao sujo e ao escancarado: "a pornografia é o erotismo dos outros", pelo escritor francês Alain RobbeGrillet. Distinção que, mais uma vez, renega aos porões o universo da sexualidade, do corpo e dos prazeres através de um argumento moralista. Quando a exposição dos órgãos sexuais é considerada repugnante, novamente é reposta a idéia dos valores elevados do belo, que teriam como alteridade esse lado baixo.

$\mathrm{Na}$ trilha de Bataille, Moraes propõe repensarmos a pornografia como um trailler que anuncia o erotismo, "uma caricatura da verdade inexorável do erotismo: o êxtase, a vertigem, o excesso":

\footnotetext{
9 MORAES, Op. Cit., p. 47.

${ }^{10}$ MORAES, Op. Cit., p. 48.

${ }^{11}$ MORAES, Op. Cit., p. 50.
} 
"Se o erotismo se define pelo segredo, a tentativa de desvendá-lo é sempre transgressora. E a transgressão, como vimos a pouco, é um ato cultural: só ela pode dar sentido à proibição. Se a pornografia é uma das formas organizadas de transgressão, ela ultrapassa sua própria ordenação ao anunciar algo que lhe escapa: o erotismo". ${ }^{12}$

O erotismo é linha de fuga, desejo e devir, nas palavras de Deleuze. Principalmente porque ele é capaz de fazer implodir as tecnologias sedentarizantes que constituem o dispositivo da sexualidade, através da liberação da imaginação criadora.

Para feministas como Judith Butler a problemática do desejo é analisada sob o prisma do poder. Critica-se aí a imposição a todos de um desejo já designado de antemão e muitas vezes autoritário. Essa é a crítica que revela o caráter particular de categorias dominantes, que não dão conta de pensar as diferenças.

Nestes termos, a poética visual de Márcia X. coincide com as preocupações dos teóricos pós-estruturalistas e das teóricas feministas, pois denuncia as violências simbólicas das opressões ao corpo, ao mesmo tempo em que investiga estratégias para derrubar as verdades legitimadas acerca da sexualidade (lembremos das manipulações sobre a imagem dos corpos principalmente dos órgãos genitais masculinos, onde $\mathrm{X}$. justamente se apropria da prática cultural de enaltecimento do masculino para criticar sua lógica falocêntrica).

Indagadas por nossos paradoxos acerca do corpo e das subjetividades, estas produções artísticas ampliam nosso universo sensível, pois desestabilizam as bases sobre as quais postulamos o conceito de identidade, ao mesmo tempo em que potencializam uma experiência de conectar a arte e a vida.

\section{Bibliografia}

BASBAUM, Ricardo, “X”: Percursos de alguém além de equações”, In. Concinnitas. Revista do Instituto de Artes da UERJ.

DELEUZE, Gilles; Crítica e Clínica. São Paulo: Ed. 34, 1997.

DELEUZE, Gilles, Mil Platôs I, São Paulo, Editora 34, 1995.

FOUCAULT, Michel, História da Sexualidade I, A vontade de Saber, Rio de Janeiro, Graal, 1977.

HOLANDA, Heloisa Buarque de, "Novos Tempos", In. Revista eletrônica Labrys - Estudos Feministas, número 3, janeiro/julho, 2003.

MORAES, E. R.; LAPEIZ, Sandra . O que épornografia. São Paulo: Brasiliense, 1984.

\footnotetext{
12 MORAES, Op. Cit., p. 59.
} 
RAGO, Margareth, "O Corpo Singular", prefácio ao livro Corpos e Subjetividades em exercício interdisciplinar, Sônia Cabeda e Marlene Neves Strey, Porto Alegre, EDIPUCRS, 2004.

RAGO, "O corpo sensual”, Anais Seminário Internacional Fazendo Gênero 7, Florianópolis, UFSC, 2006. 